\title{
النشر الاكاديمي في المبلات العراقية - واقعه وسبل الارتقاء به -
}

1.0م. د. هـب11

كلبة الآداب / جامعة ذي قار

|

أن الدور الرئيسي السليم للجامعة هو نقل المعرفة عن طريق التدريس والتعليم، فضلاً عن إثراء المعرفة من خلال البحث العلمي الرصين، وهو الهدف الاسمى والاهم. لذا يعد البحث العلمي في الدول المتقدمة خاصة، الدعامة الأساسية للاقتصاد والتطور ــ وتعد المجلات العلميـة المحكمة *الوعـاء الرئيس الذي يستقطب تلك البحوث، وفي بلداننا العربية أصبحت الحاجـة إلى البحث العلمي ضرورة قصوى بعد أن أدرك الجميع أهميته و عظم دوره في التقدم والتنمية. يتمثل هدف البحث (Aim of Research) بدر اسـة وبيـان العوامـل المـؤثرة في النشـر الاكاديمي في الجامعات العر اقية، والتأكيد على الو اقع الحالي للمجلات الاكاديمية وسبل الارتقاء بعملها بوصفها الوعاء الرئيس للنشر البحث العلمي، فضلاً عن دورها في التنمية البشرية التي تركز على لـى الانسان بوصفه هدفاً وغاية ووسيلة.

وفيما يتعلق بمنهجية البحث (The Method of Research) فقد تم الاعتماد على المنهج الوصفي التحليلي في دراسة العديد من المشاكل و المتغير ات المتعلقة بالمشكلة قيد الدراسة . وفيما يتعلق بمصـادر الدراسـة (Bibliography of Study) فقد تم الاعتمـاد على البيانـات و الإحصاءات التي وفرتها الجهات الرسمية المتمثلة بوزارة التعليم العالي والبحث العلمي ، فضـلاً عن المصادر المكتبية والاحصاءات العالمية وتقارير الأمم المتحدة. أمـا هيكليـة البحث (Arrangement Research) فقد اقتضـت الضـرورة العلميـة تقسيم البحث الى محاور عدة، تناول المحور الأول بيان واقع المجلات الاكاديمية في العراق والمعوقات التي تو اجـه عملهـا في حين ركز المحور الثـاني على أهميـة البحـث العلمي ومشـاكله. و انتهى البحـث بالاستتتاجات والتوصيات التي يرى فيها الباحث الحلول المنطقية لمعالجة المشكلة قيد الدراسة أعقبها قائمة بالمصادر و المر اجع التي تم الاعتماد عليها .

\section{اهد|ف نشمر البموث المثمية:ة}

ا - نقل المعرفة بكل ابعادها للمتلقي.

r- التواصل المستمر مع مجتمع البحث. rـ اضافة كل ما هو جديد الى حقل المعرفة. 


$$
\text { عـ التدريب في مجال البحث العلمي. }
$$

هـ تحقيق غايات شخصية منها التميز و الترقية العلمية.

الجدول (1) المجلات الاكاديمية في العراق بحسب الجامعات واختصاص المجلة

\begin{tabular}{|c|c|c|c|c|c|c|c|c|}
\hline المجموع & الانسلات & الطبيعية & الاجتماعية & الزجراتلات & المجلات & الطجلات & الجامعة / الهيئة & $ت$ \\
\hline 36 & 6 & 5 & 13 & 1 & 5 & 6 & بغذاد & .1 \\
\hline 6 & 0 & 1 & 2 & 0 & 1 & 2 & النهرين &.$Y$ \\
\hline 3 & 3 & 0 & 0 & 0 & 0 & 0 & العراقية &.$r$ \\
\hline 13 & 2 & 1 & 9 & 0 & 1 & 0 & المستتصرية &.$\varepsilon$ \\
\hline 3 & 0 & 0 & 0 & 0 & 3 & 0 & التكنولوجية & .0 \\
\hline 20 & 4 & 3 & 7 & 2 & 1 & 3 & الموصل & .7 \\
\hline 5 & 1 & 1 & 2 & 1 & 0 & 0 & كركوك &.$V$ \\
\hline 13 & 5 & 1 & 2 & 1 & 1 & 3 & تكريت &.$\wedge$ \\
\hline 12 & 5 & 1 & 2 & 1 & 2 & 2 & الاتبار & .9 \\
\hline 7 & 2 & 1 & 1 & 1 & 1 & 1 & ديالى & .1. \\
\hline 17 & 4 & 4 & 4 & 2 & 1 & 2 & الكوفة & .11 \\
\hline 11 & 5 & 2 & 2 & 0 & 1 & 1 & بابل & $.1 Y$ \\
\hline 8 & 2 & 0 & 3 & 1 & 0 & 2 & كربلاء & $.1 \%$ \\
\hline 23 & 5 & 2 & 8 & 4 & 2 & 2 & البصرة & $.1 \varepsilon$ \\
\hline 11 & 2 & 2 & 3 & 1 & 1 & 2 & القادسية & .10 \\
\hline 5 & 2 & 0 & 2 & 0 & 0 & 1 & واسط & .17 \\
\hline 6 & 2 & 1 & 1 & 0 & 1 & 1 & المثنى & $.1 \mathrm{~V}$ \\
\hline 8 & 1 & 2 & 2 & 1 & 1 & 1 & ذي قار & .11 \\
\hline 1 & 1 & 0 & 0 & 0 & 0 & 0 & ميسان & .19 \\
\hline 1 & 0 & 0 & 0 & 1 & 0 & 0 & القاسم الخضراء &.$r \cdot$ \\
\hline 1 & 0 & 0 & 0 & 0 & 1 & 0 & هيئة التعليم التقني & .41 \\
\hline 1 & 0 & & 0 & & 1 & 0 & الكرخ للعلوم الحديثة &.$Y Y$ \\
\hline 3 & & 1 & 1 & & & 1 & صلاح الدين &.$Y Y$ \\
\hline 2 & & 2 & & & & & مدينة العلم &.$Y \varepsilon$ \\
\hline 3 & & & 1 & 1 & 1 & & وزارة الزراعة والتربية والنفط &.$r \theta$ \\
\hline 2 & & & & $r$ & & & جمعية علوم التربة والدواجن & .87 \\
\hline 13 & 7 & 3 & 1 & & & 2 & اخرى* &.$Y V$ \\
\hline 233 & 59 & 31 & 68 & 20 & 24 & 33 & المجموع &.$r \wedge$ \\
\hline
\end{tabular}

المصدر: جمهورية العراق، وزارة التعليم العالي والبحث العلمي،

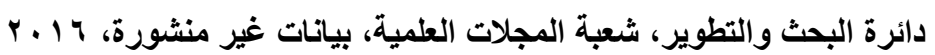

* الاخرى تشمل المجلس العر اقي الاختصاصات الطبية و الجمعية العر اقية للبحوث التربويـة والنفسية و جمعيـة القـانون المقـارن وكليـة بغـداد للعلـوم الاقتصـادية وجامعـة جـابر ان حيـان للعلـوم الطبيـة و الصيدلانية وجامعة ابن سينا للعلوم الطبية و الصيدلانية فضـلا عن جامعة اهل البيت وكلية الامـام الاعظم و الكلية الاسلامية الجامعة 


\section{الشكل (1) المجلات الاكاديمية في العراق بحسب الجامعات واختصاص المجلة}

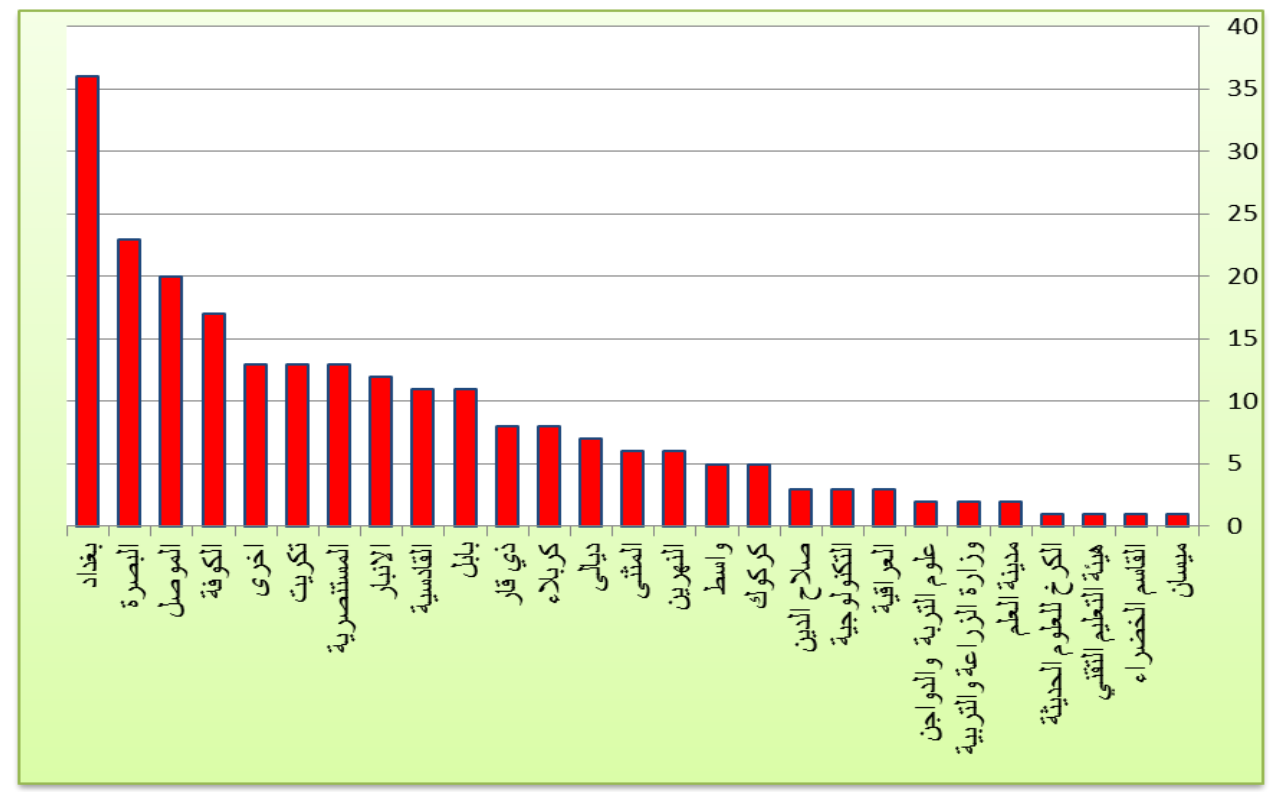

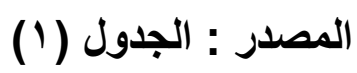

يتبين من الجدول ( () و الثكل ( () ان جامعة بغداد احتلت المرتبـة الاولى في اعداد المجلات الاكاديمية التي بلغت (Tr) مجلة منها (r ( ) للمجلات الانسانية و الطبية ، بينما احتلت جامعة البصرة المرتبـة الثانيـة بـ(YT) مجلـة، ثمـان منهـا للمجالات الاجتماعيـة، في حين احتلت جـامعتي الموصل و الكوفة المرتبتين الثالثة والرابعة على التو الي، اذ بلغت اعداد المجلات فيهما . ب و V على الترتيب. اما الجامعات المستحدثة فقد بلغت فلم تتجاوز اعداد مجالاتها مجلة و احدة فقط ومنها جامعة ميسـان و القاسم الخضـر اء. و هنـالك مجلات علميـة محكمة تابعة لوز ارة الصـناعة و التربيـة و الزر اعـة وبو اقع مجلة و احدة لكل وزارة.

\section{هعوقات البمث العامي في الباهمات العراقية}

يبين الجدول (r) عدد البحوث المنشورة من قبل التدريسيين في الجامعـات العر اقيـة وهي على الرغم من تنامي اعدادها بوتيرة منصاعدة، إلا انها في الاغلب بعيدة عن الجانب التطبيقي، فضـلاً عن ذلك فهذه البحوث لم تسوق ولم يتم تفعيلها من قبل الدوائر والمؤسسات بل بقيت اسيرة الرفوف، الامر الذي زاد الفجوة بين الانتاج العلمي والتنمية باتجاهاتها المختلفة، ومن خلال الجدول السـابق يتضـح ان

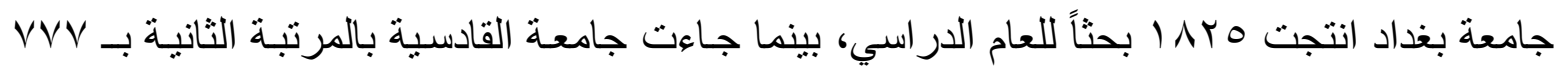
بحثا منشـوراً، ويعـاني البحث العلمي في الجامعـات العر اقيـة مـن جملـة مـن المعوقات تتمثنل بعدم وجود استر اتيجية و اضحة للبحث العلمي، فضلاً عن عدم تخصيص ميز انية مستقلة ومشجعة للبحوث 
أن الجامعات العر اقية وعلى وتيرة معظم الجامعات في الدول النامية تركز على عملية التدريس أكثر من تركيز ها على البحوث العلمية، وكأن الجامعـة حلقة يدخلها الطالب بعد الإعداديـة للحصول على الوظيفة، وهذا ليس الدور الرئيس للجامعة لأنها من المفترض ان تكون مركز اشعاع حضـاري و ثقافي وتكون قائدة للمجتمع تساهم في صنع قرار اته السياسية والاقتصـادية والاجتماعيـة، فضـالُ عن افتقار أغلب المؤسسات العلمية إلى أجهزة متخصصة بتسويق الأبحاث ونتائجها إلى الجهات المستفيدة وفق خطة اقتصادية، مما يدل على ضعف التنسيق بين مر اكز البحوث والقطاع الخـاص. كذللك غياب المؤسسات الاستشارية المختصة بتوظيف نتائج البحث العلمي وتمويله من أجل تحويل تلك النتائج إلى مشرو عات اقتصادية مربحة. إضافة إلى ضعف القطاعات الاقتصـادية المنتجـة و اعتمادهـا على شر اء المعرفة .

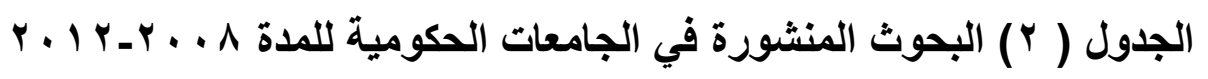

\begin{tabular}{|c|c|c|c|c|c|}
\hline $\begin{array}{l}-r+11 \\
r .1 r\end{array}$ & $r \ldots q-r \ldots \Lambda$ & الكليات & $\begin{array}{l}-r+11 \\
r+1 r\end{array}$ & $r \ldots q-r \ldots \Lambda$ & الكليات \\
\hline$\Lambda Y$ & 97 & جامعة القادسية & YYOI & $10 V \wedge$ & جامعة بغداد \\
\hline 1.0 & 90 & جامعة كربلاء & 798 & $7 \wedge 9$ & جامعة الموصل \\
\hline$\Lambda 0$ & $\Delta V$ & جامعة واسط & INY & rot & جامعة البصرة \\
\hline $1 Y \Lambda$ & $7 \varepsilon$ & جامعة ذي قار & Y97 & YOY & جامعة تكريت \\
\hline 91 & $\leqslant 7$ & جامعة ميسان & $\overline{\Lambda V}$ & $r \wedge$ & جامعة كركوك \\
\hline$r \wedge q$ & $r .7$ & جامعة الانبار & 19. & 199 & جامعة ديالى \\
\hline$V Y$ & $r \Lambda$ & جامعة المثنى & 291 & ro. & الجامعة المستتصرية \\
\hline$\varepsilon+1$ & $r \cdot 1$ & جامعة النهرين & $1 V$ & ro & الجامعة العراقية \\
\hline $1 \cdot 7$ & 07 & المجلس العراقي & $\mathrm{V}$ & 187 & الجامعة التكنولوجية \\
\hline rVY & rYr & هيئة التعليم التقتي & rqY & 194 & جامعة الكوفة \\
\hline $7 \leq 94$ & $0 \leqslant 91$ & المجموع & $r \mid r$ & rvi & جامعة بابل \\
\hline
\end{tabular}

المصدر : جمهورية العراق، وزارة التعليم العالي والبحث العلمي ، دائرة البحث والتطوير،

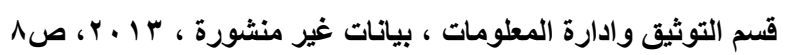

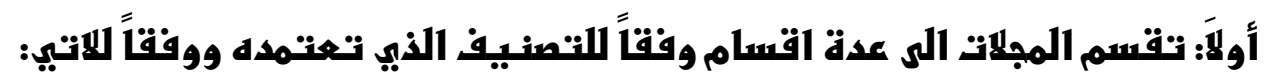

اـ المجلات المحكّمـة: وهي المجلات التي ترسـل بحوثها الى المحكمين، فضـلا عن اعتمـاد قو اعد

$$
\text { بياناتها وسلاسل فهرستها لدى المؤسسات الأكاديمية العالمية . }
$$

r- المجلة المصنفة عالميا: وهي المجلات المدرجة في الفهارس وقو اعد البيانات العالمية

بـ المجلة المتخصصة: هي المجلات التي تختص في مجالات علميـة دقيقة لأنها تصدر من مر اكز ووحدات متخصصة في فروع علمية معينة . 
عـ المجلة العالمية: وهي المجلات الددرجة ضمن سلسلة الفهارس العالمية وتتكون هيئتها الاستشـارية وهيئة تحرير ها من المتخصصين في مجال معين ومن ذوي النشاطات العلمية. و عمومـا يمكن ادر اج مشـاكل البحث العلمي في المجلات الاكاديمية للجامعات العر اقيـة من

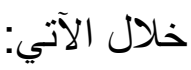
ا - عدم وجود خطط و اضحة لاتباع السياسات الكفيلة برفع قيمة معامل التأثير من خلال رفع المستوى العلمي للمجلة بشكل فعلي. r- ان ضعف البحوث العلمية وركاكة بعضهـا وعدم التطرق الى مشكلات محلية و اقليمية و عالميـة معاصرة قلل من نسب الاستشهاد، و هذا ما اظهره تصنيف (كوكل سكولر) الذي يعتمد على تصنيف

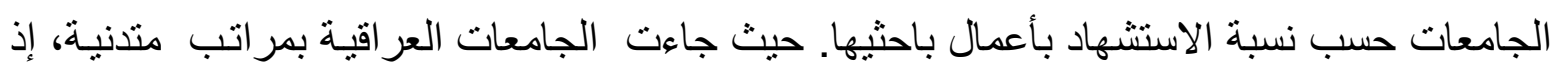

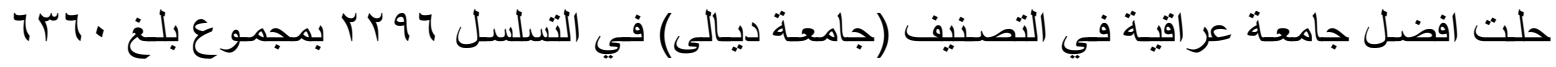
استشهاد، و هذا العدد من الاستشهادات ربما يحصل عليه باحث واحد من جامعة اوربية .

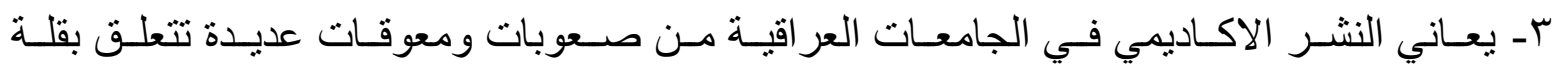
التخصيصات المالية، كما هو الحال بالنسبة للاول العربية، اذ يشير تقرير اليونسكو عن العلوم لعام 2010أن الدول العربية هي الأقل انفاقًا على البحث العلمي، ووفق الاحصـائيات الصـادرة عنها فـان

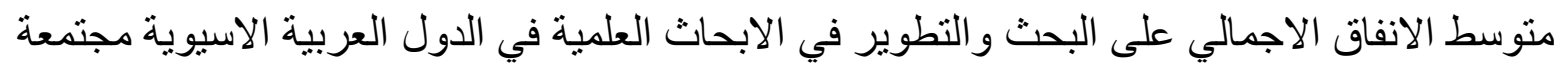

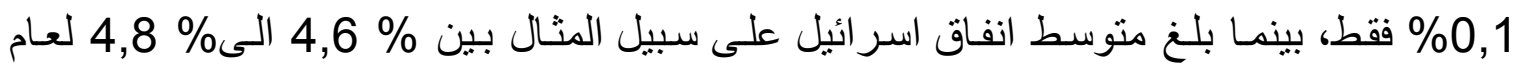

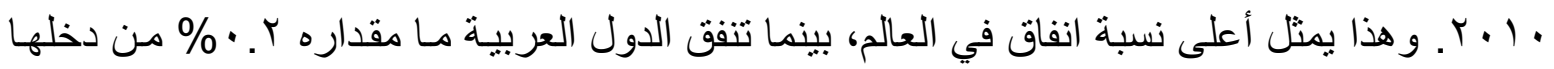

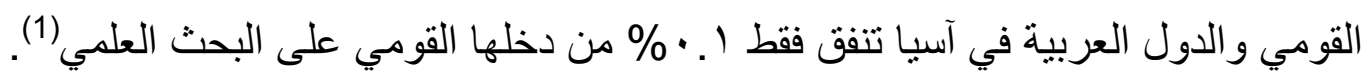
ـ- ان الهدف الباحث العر اقي من خلال بحثه الى الترقية العلمية فهو يهئ البحث وفق المنطلبات التي

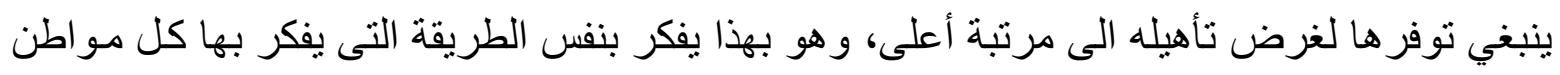
لتوفير حياه كريمة وسكن ملائم ومتطلبات الحياة الاخرى ، ويعتبر ذللك من احد اهم التحديات التي

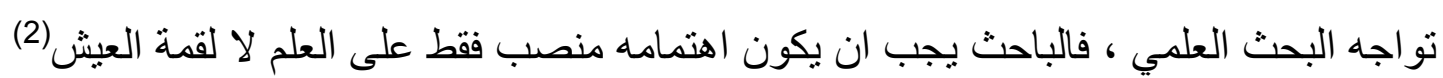
هـ أن بعض البحوث العلمية في الجامعات العر اقية تتسم بالتقليد و الدحاكاة دون اللجوء إلى الابداع و الابتكار لان اهدافها لا تتعدى مسالة الترقية العلمية ، مما أدى إلى عزل نشاطات الجامعة البحثية عن نثاطات القطاعات المجتمعية الاخرى . جـ أن ضعف القدرات و البنى التحتية انعكس على طبيعة البحث العلمي ، الأمر الذي جعله بعيدا عن متطلبات التتمية. 
V- عدم وجود تعاون حقيقي بين الجامعة ومؤسسات الدولة ودو ائر ها الحكومية و الخدمية والانتاجية ،

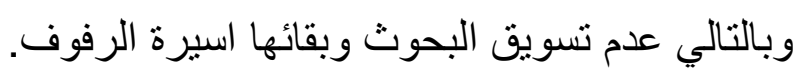

يـ قلة اعداد الباحثين وهو أمر تمتاز به الجامعات العربية عموما ، فتقرير اليونسكو لم يذكر بالتحديد

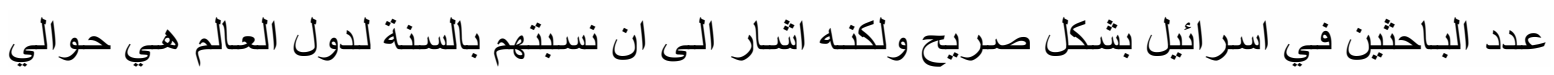

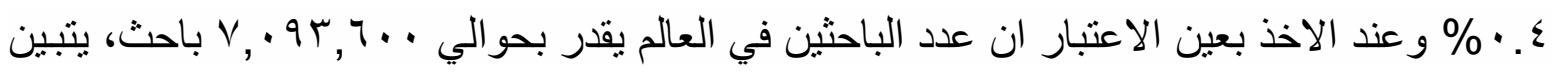

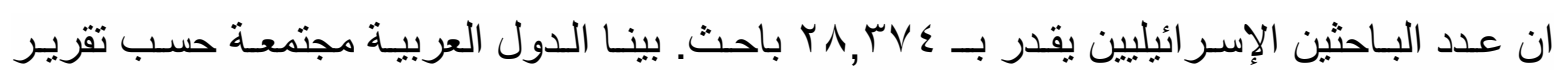

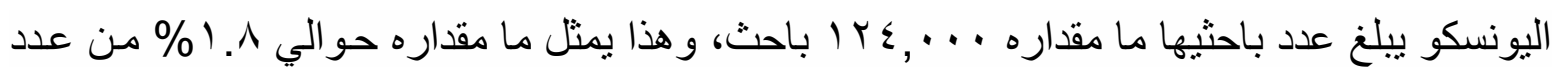

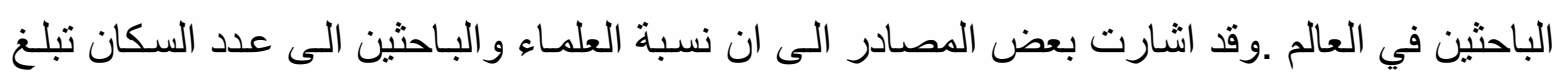

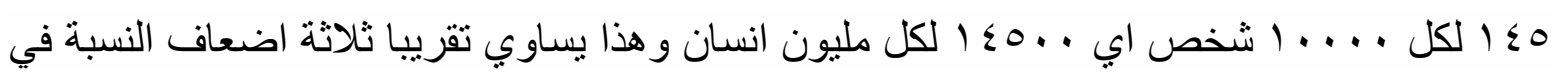

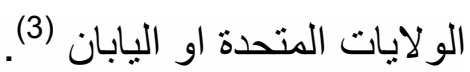
9- تعاني الجامعات العر اقية بشكل عام من أزمة تتمثل في ضـف البنى البحثية في مجالات البحث

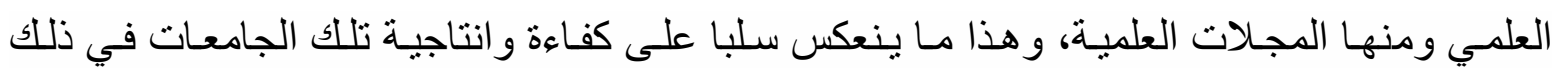

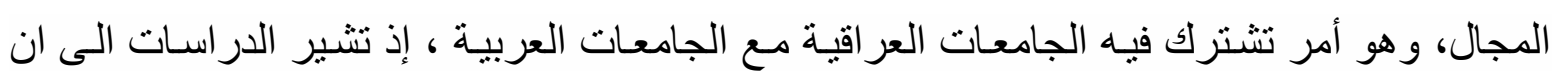

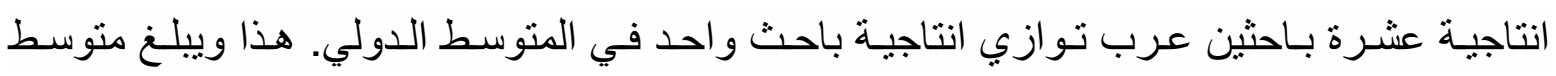

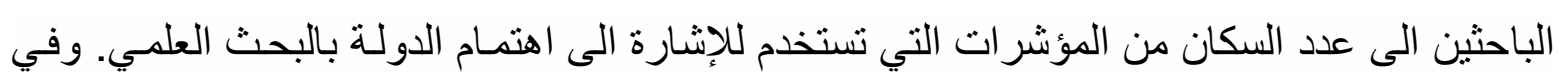

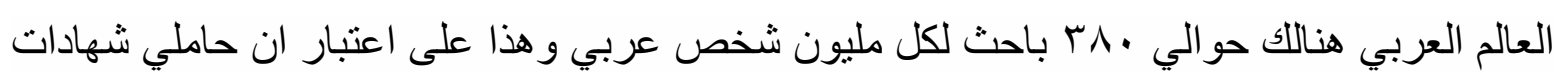

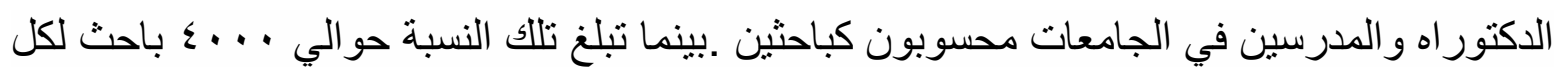

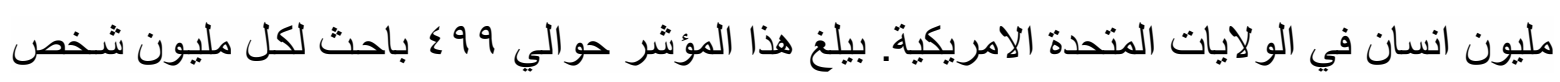

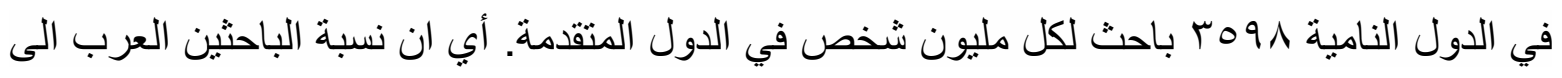

$$
\text { عدد السكان هم الادنى في كل دول العالم . }
$$

• اـ تعاني الجامعات العر اقية من قلة إنتاجية الباحث الواحد ، شأنها شأن الجامعات العربية التي بلغت

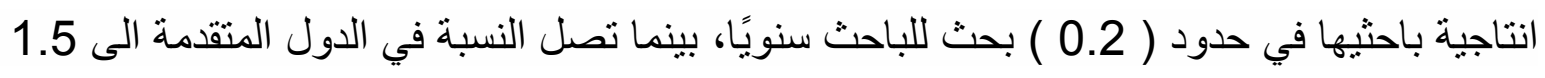
بحث للباحث الو احد سنويًا ، ويصل معدل الإنفاق على البحث والتطوير في المنطقة العربية إلى لى

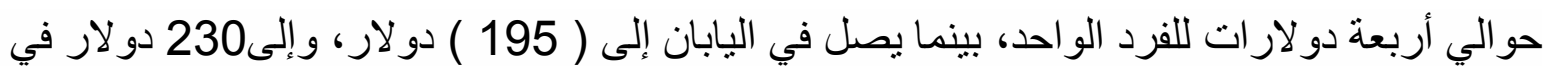

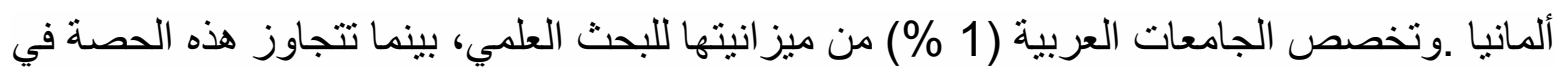

الو لايات المتحدة 40\% 
التوصيات

ا - يوصـي الباحث بالعمل على تو أمـة البحث العلمي في الجامعـات العر اقيـة مـع البحث العلمي في الجامعـات العالميـة مـن اجل تشـيع البـاحثين العـر اقيين للعمـل مـع بـاحثين اجانب وذللك للاحتكـالك بالخبر ات العالمية وبعالم التقنيات والتكنولوجيا البحثية وحثهم على نشر اعمالهم البحثية في المجلات العلمية لتلك الدول. كل ذلك و غيره سنعكس ايجاباً على نمو البحث العلمي وتطوره في العراق. r- ان و اقع المجلات العلمية يتطلب اعادة تصنيف وهيكلة لبعض المجلات، وكذلك التعاقد مع مجلات علمية اقليمية و عالمية معروفة سيعزز من قيمة ومصداقية البحوث المنشورة. بـ تلافيا للانتحال العلمي ينبغي انشاء نظام الكتروني بهدف ارشفة البحوث و المحافظة على الملكية الفكرية.

عـ ان ارتفاع قيمة معامل التأثثير يعتمد على عدد الاستتـهادات خـلال السنتين الاخيريتين من عمر المجلة، لذا يفضل ان تقوم المجلة بنشر البحوث الميدانية والحقلية، التي يكثر الاستشهاد بها بشكل أكبر من غير ها لأنها تقدم إضافة علمية جديدة لحقول المعرفة. هـ يجب اعـادة النظر بـالأجور المخصصسة للمقومين، وان تكون هنـاك در ايـة بتخصس الباحـ، و لابأس ان يرسل البحث الى ثناث خبر اء مع وضع آلية دقيقة لمتابعة النتائج و التعديلات .

\section{المسادر والهواهش}

* المجلة العلمية المحكمة عبارة عن دورية علمية تتشر أبحاثاً متخصصة في مجال محدد بعد أن تقوم بتحكيم هذه الأبحاث من قبل

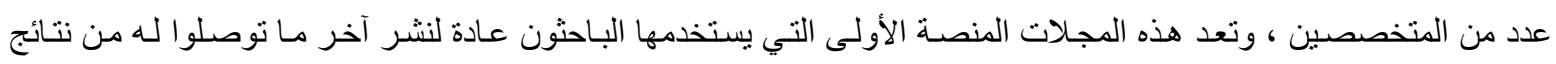

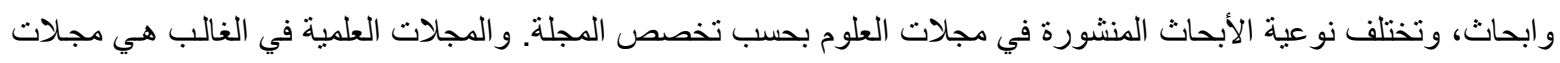

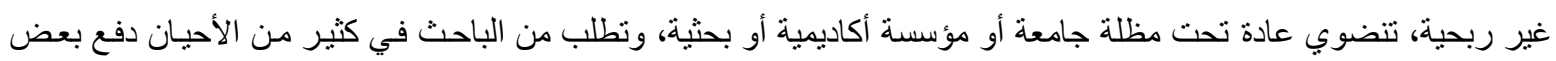
تكاليف الطبع و النشر

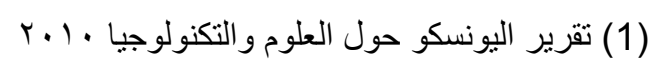

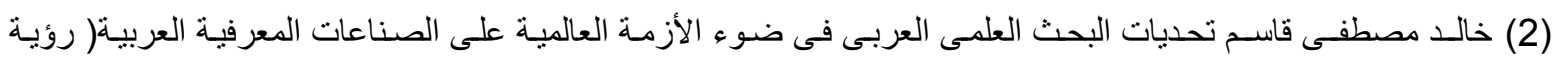

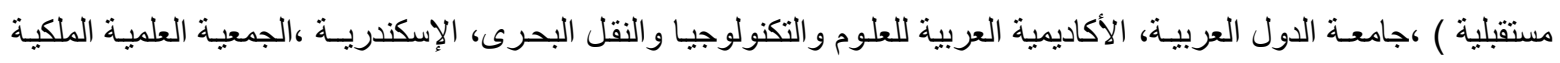

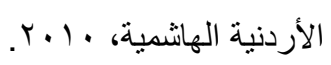

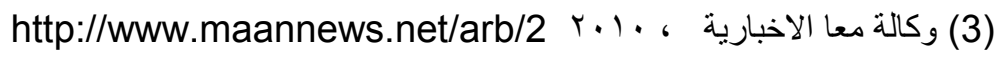

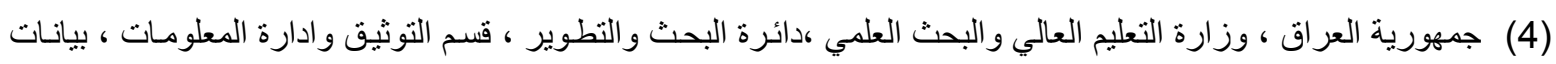

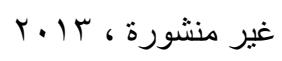

(5)جمهوريـة العراق ، وزارة التعليم العـالي والبحث العلمي ،دائرة البحث و التطوير ،. شـعبة المجلات العلميـة، بيانـات غير

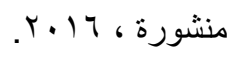

(6) عماد أحمد البرغوثي ومحمود أحمد أبوسمرة ، مشكلات البحث العلمي في العالم العربي ، مجلة الجامعة الإسلامية ،جامعة

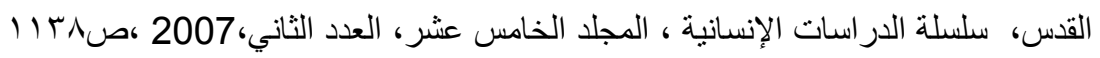

